\title{
FAILED ACROMIOPLASTY FOR IMPINGEMENT SYNDROME
}

\author{
D. J. OGILVIE-HARRIS, A. M. WILEY, J. SATTARIAN
}

From Toronto Hospital

\begin{abstract}
We evaluated 67 shoulders in 65 patients who had pain and dysfunction for more than two years after an initial acromioplasty for impingement syndrome without a rotator cuff tear. In addition to a thorough history, physical examination, local anaesthesia injection and any other necessary investigations all patients had arthroscopic evaluation of the shoulder. In 27 shoulders there had been diagnostic errors, and in 28 operative errors; only in 12 had the diagnosis and the operative procedure both been correct. Subsequent operative intervention in patients not receiving worker's compensation benefit had a $75 \%$ success rate, whereas in those receiving such benefits the success rate was only $46 \%$.
\end{abstract}

Impingement syndrome occurs when the supraspinatus tendon is compressed against the anterior inferior surface of the acromion and the coraco-acromial ligament (Watson 1989). Anterior resection of the acromion and coraco-acromial ligament produces a high percentage of successful results in properly selected patients (Neer 1972; Neer 1983; Hawkins et al 1988; Watson 1989). Hawkins et al (1988) reported $87 \%$ successful results. However there is little in the literature on the reasons for failure of acromioplasty or the management of the patient with a failed acromioplasty.

\section{PATIENTS AND METHODS}

This was a retrospective analysis of 67 shoulders in 65 patients. Twenty-one of the failures occurred in patients on whom we had operated and the others were referred from elsewhere after the initial operation had failed. There were 44 men and 21 women; 49 of the patients were aged between 30 and 60 , with 11 of the patients aged under 30 and five aged over $60 ; 39$ of the patients were receiving worker's compensation benefit.

Our definition of failed acromioplasty was persistent pain and dysfunction for two years or more following the index operation. At the initial assessment, a thorough history and physical examination were performed.

D. J. Ogilvie-Harris, FRCS C, Chief of Orthopaedic Surgery A. M. Wiley, FRCS, FRCS C, Orthopaedic Surgeon

The Toronto Hospital, Toronto Western Division, Fraser M. Fell Pavilion, 399 Bathurst Street, Toronto, Ontario, Canada M5T 2 S8.

J. Sattarian, Orthopaedic Surgeon

Scarborough Grace General Hospital, 3030 Birchmont Road, Scarborough, Ontario, Canada MIW 3 W3.

Correspondence should be sent to Dr D. J. Ogilvie-Harris.

(C) 1990 British Editorial Society of Bone and Joint Surgery $0301-620 \times / 90 / 6010 \$ 2.00$

J Bone Joint Surg [Br] 1990; 72-B : 1070-2.
Radiographs were then taken, including special views of the shoulder as necessary. Injections of local anaesthesia into the acromioclavicular joint and into the subacromial space were performed. Electrodiagnostic tests and assessment of the cervical spine by radiographs and discograms were carried out as indicated.

In addition, all the patients in this study underwent arthroscopy and examination under anaesthesia. The arthroscopy was performed with the patient in the lateral elevated position (Ogilvie-Harris and Wiley 1986). In addition to an evaluation of the intra-articular structures, the subacromial space was visualised. Arthroscopic surgery was performed on some patients when there were clear-cut indications. Subsequent to the establishment of a diagnosis, further operations were carried out; their nature depended on the pathology and included cervical fusion, rotator cuff repair, repeat acromioplasty, stabilisation of the shoulder and decompression of entrapped nerves.

The results were assessed two to six years (average 3.2) after the arthroscopic procedure. Of the 65 patients, 45 were examined; the remaining information was gathered by chart review or speaking with the patient. A successful result was considered as one in which the patient had minimal pain, had almost full range of movement, and was able to return to work. In view of the different pathologies that were found at the time of the arthroscopy, each subgroup of failed acromioplasties had to be assessed with separate specific criteria.

\section{RESULTS}

The patients were divided into three groups (Table I). In one group were patients in whom there had been diagnostic errors; these patients had obviously had the wrong operation. In the second group of patients the diagnosis had been correct, but operative errors were 
judged to have been made. In the third group were patients in whom we felt that the correct diagnosis had been made and the correct operation performed, but who still had significant pain and discomfort more than two years after the original acromioplasty. There were 27 shoulders in which there were diagnostic errors, 28 in whom there were operating errors, while 12 had had both the correct diagnosis and the correct operation.

Table I. The correctness or otherwise of diagnosis and operation in the 67 shoulders

\begin{tabular}{lll}
\hline Group & Diagnosis & Operation \\
\hline $\begin{array}{l}\text { Diagnostic } \\
\mathrm{n}=27\end{array}$ & $\mathrm{X}$ & $\mathbf{X}$ \\
$\begin{array}{l}\text { Operative } \\
\mathrm{n}=28\end{array}$ & $\checkmark$ & $\mathbf{X}$ \\
$\begin{array}{l}\text { Correct } \\
\mathrm{n}=12\end{array}$ & $\checkmark$ & $\checkmark$ \\
\hline
\end{tabular}

Diagnostic errors. The diagnostic errors were divided into three subgroups - those with referred pain, those with intra-articular pathology, and those with extraarticular pathology (Table II). It can be seen that almost a quarter of the patients with diagnostic errors had referred pain. The patient with the thoracic outlet syndrome and the patient with ulnar nerve entrapment were treated operatively with relief of their symptoms; of the five patients whose pain was referred from the cervical spine, three underwent cervical fusion but only one had a successful result.

Of the 11 patients with significant intra-articular pathology, two had osteoarthritis of the glenohumeral joint; these were treated by arthroscopic debridement, but only one had relief of symptoms. In both the patients with major glenoid labrum tears (small tears are probably not symptomatic), these tears were resected, and both patients had relief of their symptoms.
Of the seven patients with instability of the shoulder, four had anterior instability, in the other three it was multi-directional. In each case the instability was recognised at examination under anaesthesia and confirmed at arthroscopy, but in none had the diagnosis been considered pre-operatively. Two of the three patients with multi-directional instability were treated operatively, but only one had a successful result. The four patients with anterior instability were repaired using the method of Putti-Platt and three were successful.

Three of the patients in the extra-articular group had a classic frozen shoulder, which had developed as a complication of the original acromioplasty. At the time of our arthroscopy, all three were found to have evidence of minor intra-articular pathology with partial degeneration of the rotator cuff and mild synovitis; an intraarticular debridement, followed by manipulation to restore movement, relieved the symptoms in two of these three patients. The remaining six patients in this extraarticular group had a rotator cuff tear, which had not been recognised at the original acromioplasty. We found it impossible to tell whether the tear had been present at that time or had developed later; the former seems more likely. We repaired the torn cuff at our arthroscopy in all six patients, but in only three was it successful.

Operative errors. Of the 28 patients in whom operative errors had been made in the management of their impingement syndrome, five had significant pain and discomfort in the acromioclavicular joint. This was confirmed by injection of local anaesthesia into the joint, with relief of symptoms; these five patients underwent excision of the acromioclavicular joint and in three the result was successful. Eleven of the 28 patients had adhesions in the subacromial space extending into the area of the biceps tendon. At the time of our arthroscopy we removed these adhesions and fibrous scar tissue using a power shaver, but only six had relief of their symptoms.

In 12 patients we felt that insufficient bone had been resected from the undersurface of the acromion or the coraco-acromial ligament had not been resected. This

Table II. Details of the 67 failures, their subsequent treatment and its result

\begin{tabular}{lllccc}
\hline Failures & Subgroups & Correct diagnosis & Number & $\begin{array}{c}\text { Operation } \\
\text { performed }\end{array}$ & $\begin{array}{c}\text { Good } \\
\text { result }\end{array}$ \\
\hline & \multirow{2}{*}{ Referred (7) } & Thoracic outlet & 1 & 1 & 1 \\
& & Cervical spine & 5 & 3 & 1 \\
& & Ulnar nerve & 1 & 1 & 1 \\
Diagnostic & Intra-articular (11) & Osteoarthritis & 2 & 2 & 1 \\
errors (27) & & Labrum tears & 2 & 2 & 2 \\
& & Instability & 7 & 6 & 4 \\
& \multirow{2}{*}{ Extra-articular (9) } & Frozen & 3 & 3 & 2 \\
Operative & & Rotator cuff & 6 & 6 & 3 \\
errors (28) & & Acromioclavicular & 5 & 5 & 3 \\
& & Adhesions & 11 & 11 & 6 \\
Correct (12) & & Bone +c-a lig & 12 & 12 & 6 \\
Total & & & 12 & 0 & 1 \\
\hline & & & 67 & 52 & 31 \\
\hline
\end{tabular}


was a subjective assessment based on the presence of preoperative impingement relieved by injections of local anaesthesia into the subacromial space, by assessment of radiography, and by the findings at our arthroscopy and subsequent exploration. In all 12 patients a further acromioplasty and resection of the coraco-acromial ligament was performed (in five, the ligament had been intact). We could not determine whether the coracoacromial ligament had not been resected by the original surgeon or whether it had been divided and subsequently re-attached. In view of this, we would recommend excising a portion of the ligament rather than merely dividing it. Six patients had a successful result from the repeated acromioplasty.

No errors. In 12 of the patients, we felt that both the original diagnosis and the original operation had been correct. Our investigations, including arthroscopy, revealed nothing that would account for the patient's continuing pain and discomfort. For these patients we offered a pain management programme, but at the time of follow-up only one had relief of symptoms.

Patients receiving worker's compensation benefit. Patients receiving worker's compensation benefit overall did significantly worse than those not receiving such benefit. Of the 52 operations performed, 31 were successful $(60 \%)$. Of the 28 performed in patients receiving benefit, only 13 were successful $(46 \%)$; in those not receiving compensation payments, 18 of the 24 were successful $(75 \%)$. Of the patients treated non-operatively, only one of 11 from the worker's compensation group had relief of symptoms over the period of follow-up.

\section{DISCUSSION}

From this study it is apparent that a careful history, physical examination and evaluation of the patient can reduce the number of failed acromioplasties. The majority of the diagnostic errors were probably due to inadequate pre-operative evaluation. We consider that the history and physical examination (including the use of injections of local anaesthesia) are the most important steps in the correct evaluation of a patient for acromioplasty (Kessel and Watson 1977; Neer and Welsh 1977; Watson 1989). In evaluating the failed acromioplasty, we found arthroscopy was particularly useful for the assessment of diagnostic errors.

It was interesting to note that one-quarter of all diagnostic errors were due to instability of the shoulder. The relationship between shoulder instability and the impingement syndrome is not clear. Patients with instability may have symptoms and signs of impingement, presumably due to the deranged mechanics of the shoulder. However, acromioplasty is not the appropriate treatment for these patients; they need repair of the unstable shoulder.

During the operative treatment for impingement, it is important to remove sufficient bone from the anterior portion of the acromion (Hawkins et al 1988). Neer (1972) recommended that the anterior $1.5 \mathrm{~cm}$ should be resected along with a portion of the coraco-acromial ligament. In 12 of our patients with operative errors, insufficient bone had been resected, and in five cases the coraco-acromial ligament was still intact.

In five of our patients, there was obvious disease in the acromioclavicular joint. At the time of the initial acromioplasty, this joint should be excised if there is significant degenerative change (Watson 1989). For the failed acromioplasty, subsequent removal of a diseased acromioclavicular joint offers a reasonable chance of success.

In the 12 patients with what we considered to have been the correct diagnosis and the correct treatment, we were, despite extensive investigation, unable to elucidate the cause of the continuing pain and dysfunction; only one had significant relief from a pain programme. The cause of failure in this group could not be determined, but it is probably significant that 10 of the patients were receiving worker's compensation benefit.

Overall, patients receiving this benefit did much worse than those who were not. However, even in those patients receiving benefit, some patients gained from repeated surgical procedures. We found it was impossible to predict with any degree of certainty which patients were going to respond well to surgical intervention. Poor results after anterior acromioplasty in patients receiving compensation benefit have also been reported by Hawkins et al (1988) who had 14 patients with poor results in their series of 108 acromioplasties.

Conclusions. Careful evaluation of the patient presenting with shoulder pain can eliminate many of the causes for a failed acromioplasty. In patients not receiving worker's compensation benefit, an overall success rate of $75 \%$ can be expected in treating surgically correctable lesions. In the group receiving benefit, the results are only $43 \%$ successful, but it was not possible to predict which patients would have improved results from surgery prior to operation.

No benefits in any form have been received or will be received from a commercial party related directly or indirectly to the subject of this article.

\section{REFERENCES}

Hawkins RJ, Brock RM, Abrams JS, Hobeika P. Acromioplasty for impingement with an intact rotator cuff. J Bone Joint Surg [Br] 1988; 70-B:795-7.

Kessel L, Watson M. The painful arc syndrome: clinical classification as a guide to management. J Bone Joint Surg $[\mathrm{Br}]$ 1977; 59-B: 166-72.

Neer CS II. Anterior acromioplasty for the chronic impingement syndrome in the shoulder: a preliminary report. J Bone Joint Surg [Am] 1972; 54-A :41-50.

Neer CS II. Impingement lesions. Clin Orthop 1983; 173:70-7.

Neer CS II, Welsh RP. The shoulder in sports. Orthop Clin North Am $1977 ; 8: 583-91$.

Ogilvie-Harris DJ, Wiley AM. Arthroscopic surgery of the shoulder. $J$ Bone Joint Surg [Br] 1986; 68-B:201-7.

Watson M. Rotator cuff function in the impingement syndrome. $J$ Bone Joint Surg [Br] 1989; 71-B:361-6. 